\title{
A density functional study on synthetic polymer-amino acid interaction
}

\author{
BHABESH CHANDRA DEKA and PRADIP KR. BHATTACHARYYA*(i) \\ Department of Chemistry, Arya Vidyapeeth College, Guwahati, Assam 781 016, India \\ E-mail: prdpbhatta@yahoo.com; bhabeshdeka30@gmail.com
}

MS received 28 February 2018; revised 27 May 2018; accepted 12 June 2018; published online 20 August 2018

\begin{abstract}
Interaction of four synthetic polymers viz., poly- $\varepsilon$-caprolactone (PCL), polyglycolide (PGA), polylactic acid (PLA) and Poly(lactic-co-glycolic) acid (PLGA) used as protein delivery vectors with a few amino acids have been studied by using density functional theory. Association geometries of polymer-amino acid adduct are modelled in a vacuum and in four solvents. Nature and strength of interaction have been analyzed in terms of interaction energy and thermochemical parameters of adducts as well as vibrational frequency shifts upon adduct formation. Results suggest comprehensive stability of adducts in the gas phase. Progressive destabilization of adducts with increasing polarity of solvent is observed. Redshifts in vibrational frequencies of $\mathrm{X}-\mathrm{H}$ bonds $(\mathrm{X}=\mathrm{H}$ donor in hydrogen bonding) upon adduct formation are noticed. The study asserts the potentiality of the considered synthetic polymers as an amino acid carrier.
\end{abstract}

Keywords. Density functional theory; hydrogen bonding; synthetic polymer; amino acid; interaction energy; solvent effect.

\section{Introduction}

Since long, various aspects of the delivery of therapeutic proteins have been investigated and protein delivery remains as an active area of research owing to its wide-scale application in disease therapies, vaccination, and imaging. ${ }^{1-3}$ An ideal drug carrier must possess some indispensable characteristics like non-immunogenicity, non-toxicity, biocompatibility, and biodegradability. ${ }^{4}$ Polymer coatings have been demonstrated to represent a viable way to control protein adsorption and release. ${ }^{5}$ Although bio-polymers are the elaborately studied vectors for protein delivery, synthetic polymer-based biomaterials have also attracted intense investigations for their applications in a controlled delivery of therapeutic proteins. ${ }^{6}$ The most promising among them are a few bio-degradable and bio-compatible lactide and glycolide polymers namely, Poly- $\varepsilon$-caprolactone (PCL), Polyglycolic acid (PGA), Polylactic acid (PLA) and Poly(lactic-co-glycolic) acid (PLGA). ${ }^{2,7-10}$ Kim et al. demonstrated the suitability of PCL and its derivatives as a potential candidate for drug delivery, outlining its non-toxic behavior. ${ }^{7}$ Sinha et al. reported the ability of PCL microspheres and nanospheres in prolonging the period of insulin delivery. ${ }^{11}$ The electrospinning and matrix-controlled delivery of protein crystals by PCL has been explored recently. ${ }^{12}$ The commendable encapsulation ability of PLGA against a model protein bovine serum albumin is also reported. ${ }^{13}$ However, an abundance of proteins get adsorbed on the surfaces of polymers instantaneously once implanted into human bodies, which causes a series of subsequent glitches. ${ }^{14,15}$ Therefore, understanding the interaction between polymer vectors and biomolecules, such as proteins/peptides/amino acids, is a pre-requisite for achieving successful and optimal usage of these protein carriers. These interactions take place at atomic and molecular levels and are quite difficult to be tracked by experimental techniques. Currently, studies using density functional theory (DFT) have rekindled investigations of several aspects of the interaction between nanomaterial and biomolecules. A number of reviews addressing different aspects of protein-surface interaction have been published previously. ${ }^{11,16-18}$ There are a few computational studies of protein-polymer interactions in which the protein binding ability of polystyrene, polyethene and polydimethylsiloxane have been studied. ${ }^{19-24}$ Adsorption of bovine serum albumin (BSA) 
on hydrophilic and hydrophobic surfaces was studied using molecular modelling by Jeyachandran et al. ${ }^{19}$ They modelled two types of non-bonded interactions: long-range (electrostatic) and short range (van der Waals forces including hydrogen bonding and hydrophobic interactions). Results showed that the interaction of BSA molecules with hydrophobic surfaces took place through $\mathrm{CH}_{3}$ groups, while polar - $\mathrm{COOH}$ groups participated in the interaction on hydrophilic surfaces. $\mathrm{Lu}$ et al. had evaluated the average solvation interaction energy for four proteins on the polymer surfaces such as polystyrene, polypropylene and polyethene and the values ranged from -259.1 to $-74.1 \mathrm{~kJ} / \mathrm{mol} .{ }^{20}$ This study suggested that the most abundant hydrophobic amino acid residues on the protein surface were alanine and proline; isoleucine, leucine, and valine were observed on the protein surface only occasionally, and phenylalanine and tryptophan did not appear at all on the surface of the four proteins. Obrien et al., carried out another study employing novel molecular dynamics techniques in order to determine the change in free energy for the adsorption of a solvated peptide to a crystalline polylactide surface. ${ }^{21}$ Results predicted an adsorption free energy of $-2.5 \mathrm{kcal} / \mathrm{mol}$ and indicated a fairly strong adsorption. In a review on the performance of a biomaterial in terms of its bulk and surface properties, Refraini and Ganazzoli have elaborately stated that the interaction of amino acids with the surface is driven by dipolar and dispersive interactions, while very few hydrogen bonds are formed between the adsorbate and the surface. The interaction energy per residue in contact with the surface of graphite was calculated as $57 \mathrm{kJmol}^{-1}$, as the initial one (the same value, $56 \mathrm{kJmol}^{-1}$ for lysozyme), whereas on polyvinyl alcohol (PVA) it was equal to $38 \mathrm{kJmol}^{-1}$ indicating a weaker interaction. ${ }^{22}$ Atomistic molecular dynamics simulations were conducted by Liu et al. to shed light on the adsorption mechanism of HFBI on the PDMS substrate in an aqueous environment which predicted that van der Waals interactions are the predominant driving force for the adsorption. ${ }^{24}$

An in-depth understanding of the nature and strength of interaction between the aforementioned synthetic polymers and amino acids is essential for evaluating the efficacy of these polymers as a protein carrier. However, despite the versatility of such interactions in biological systems and their therapeutic expediency, DFT studies on them have been sparse. In view of these aspects, an attempt has been made to analyze the adduct formation between four synthetic polymers viz., PCL, PGA, PLA and PLGA and amino acid (AA) molecules which ultimately will serve a comparison of these polymers vis-à-vis their protein binding and release ability. Elucidation of the nature and strength of interaction between AAs, the building blocks of proteins and these polymeric carriers is believed to mimic to some extent a typical polymer-protein interaction and remains the focus of the current study. Stability of such adducts is gauged in terms of interaction energy and various thermo-chemical parameters. Five neutral AAs that include non-polar variants like glycine (gly), alanine (ala), phenylalanine (phe), and polar ones such as serine (ser) and asparagine (asn) are chosen for the study. Among the chosen AAs, ala and phe are hydrophobic while gly, ser and asn are hydrophilic.

\section{Computational details}

The polymeric carrier molecules considered in the present study are modelled by adopting their dimer structures. As regard to the structure of chosen AAs, the non-ionic form is considered in gas phase calculations due to larger intrinsic proton affinity of carboxylate oxygen atom as compared to a nitrogen atom of the amino group.

Application of Molecular electrostatic potential (MEP) has been remarkably successful to understand the interaction between molecules. ${ }^{25}$ In the present study, MEP surfaces of the chosen carrier and AA molecules (which are presented in Figure 1) are utilized to model various association geometries.

The existence of a number of electrons rich (depicted by red color) and/or electron deficient regions (blue color) in the MEP surfaces of the polymers and AAs clearly outlines the viability of several association geometries for a particular adduct. All the possible association geometries have been explored and optimized at M06-2X/6-31++G(d,p) level of theory. Geometrical minima of these optimized geometries are ascertained by frequency calculations at the same level of theory. However, the one possessing the minimum total electronic energy with respect to each adduct is only reported in this article. The chosen association geometries do possess a number of degrees of freedom that might lead to multiminima PES. The absence of any imaginary frequency in hessian calculations ascertain that the geometries are at the global minima on their PES. Interaction energy $\left(\Delta \mathrm{E}_{\text {int }}\right)$ of adducts, binding enthalpy $\left(\Delta \mathrm{H}_{\text {int }}\right)$ and free energy $\left(\Delta \mathrm{G}_{\mathrm{int}}\right)$ of adduct formation with all the above-mentioned geometries are calculated by using the super-molecular approach based on equations (1), (2) and (3).

$$
\Delta \mathrm{E}_{\text {int }}=\mathrm{E}_{\text {Polymer-AA }}-\left(\mathrm{E}_{\text {Polymer }}+\mathrm{E}_{\mathrm{AA}}\right)+\mathrm{E}_{\mathrm{BSSE}}
$$

where $\mathrm{E}_{\text {Polymer-AA }}$, $\mathrm{E}_{\text {Polymer }}$, and $\mathrm{E}_{\mathrm{AA}}$ are energy of adduct, polymer and AA respectively. $\mathrm{E}_{\mathrm{BSSE}}$ is the basis set superposition error (BSSE) correction calculated by using counterpoise correction method. ${ }^{26}$

$$
\begin{aligned}
\Delta \mathrm{H}_{\text {int }} & =\mathrm{H}_{\text {Polymer-AA }}-\left(\mathrm{H}_{\text {Polymer }}+\mathrm{H}_{\mathrm{AA}}\right) \\
\Delta \mathrm{G}_{\text {int }} & =\mathrm{G}_{\text {Polymer-AA }}-\left(\mathrm{G}_{\text {Polymer }}+\mathrm{G}_{\mathrm{AA}}\right)
\end{aligned}
$$



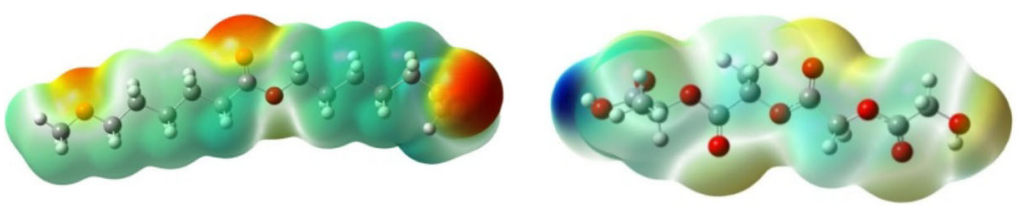

PCL

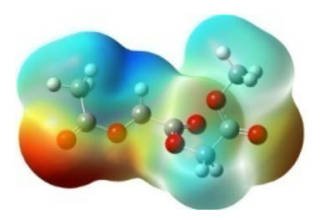

PGA

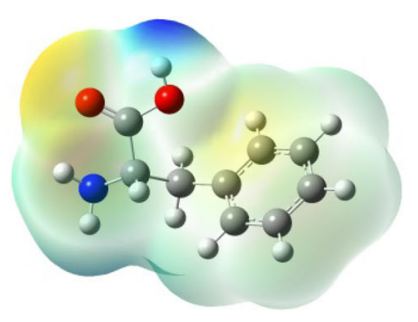

phe

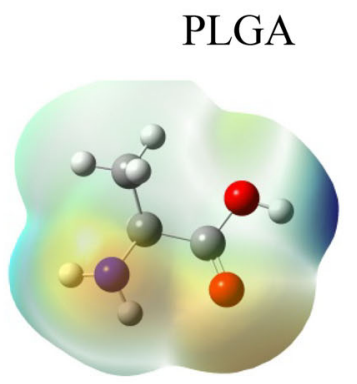

ala

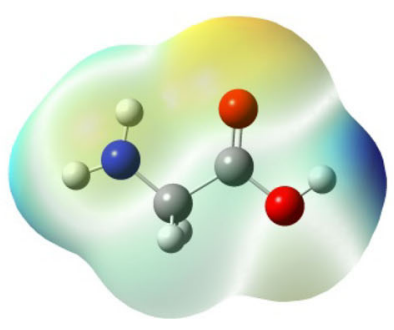

gly

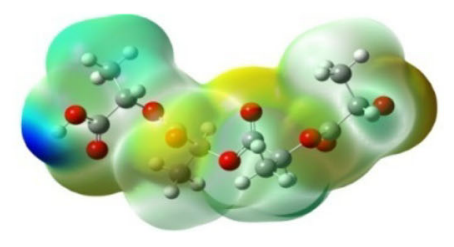

PLA

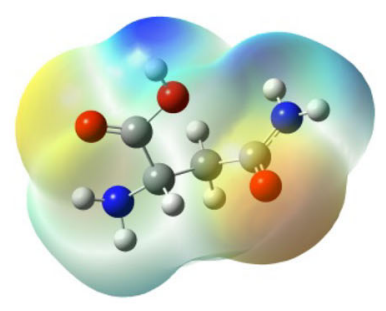

asn

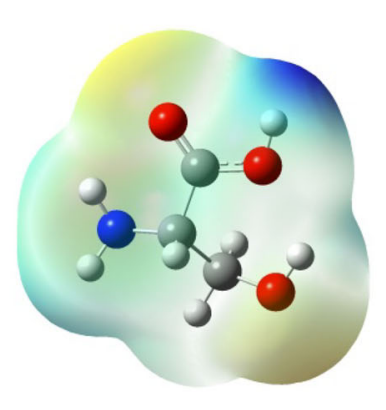

ser

\section{$\nabla_{\mathrm{H}} \Theta_{\mathrm{N}} \odot \mathrm{O}$}

Figure 1. Iso-surface diagram of considered polymer and amino acid molecules obtained at M06-2X/6-31++G(d,p) level of theory (at 0.004 au isodensity).

where, $\mathrm{H}_{\text {Polymer-AA, }} \mathrm{H}_{\text {Polymer }}$ and $\mathrm{H}_{\mathrm{AA}}$ are enthalpy of adduct, the respective polymer and the AA. G Golymer-AA, $\mathrm{G}_{\text {Polymer }}$ and $\mathrm{G}_{\mathrm{AA}}$ are the free energy of an adduct, the respective polymers and the AA. Solvent effect on the title interactions have been analyzed with the help of polarizable continuum model $(\mathrm{PCM})^{27}$ taking four different solvents covering a range of di-electric constant viz. carbon tetrachloride $(\varepsilon=2.22)$, acetone $(\varepsilon=20.49)$ dimethyl sulfoxide (DMSO, $\varepsilon=46.43)$, and water $(\varepsilon=78.35)$.

All the calculations were performed by using Gaussian 09 suite of programs. ${ }^{28}$

\section{Results and Discussion}

\subsection{Adduct formation}

Amino acids are well-known to form hydrogen bond (hb) with different carrier molecules. ${ }^{29,30}$ The optimized geometries of the adducts obtained at M06$2 \mathrm{X} / 6-31++\mathrm{G}(\mathrm{d}, \mathrm{p})$ level of theory as described in the previous section are presented in Figure $\mathrm{S} 1$ of
Supplementary Information. It is evident from Figure S1 (Supplementary Information) that there exists hydrogen bonding interaction between $\mathrm{H}$ atom of $-\mathrm{COOH}$ group of the chosen AAs and $\mathrm{O}$ atom of $-\mathrm{CO}$ or $-\mathrm{COO}$ group in the polymer molecules. Although in most of the chosen polymer-AA adducts, AAs and the polymers act as $\mathrm{H}$-donor and $\mathrm{H}$-acceptors respectively, in adducts formed by PLA and PLGA there exists two hbs. In one of the two hbs the polymer is $\mathrm{H}$ acceptor, $\mathrm{AA}$ is $\mathrm{H}$ donor and the reverse takes place in the other one. The gas phase interaction distances between the two moieties in the adducts are in the range of 1.56-1.97 $\AA$ (values are provided in Table 1. In adducts of PLA and PLGA the first value in the table denotes the hydrogen bond distance where PLA/PLGA acts as H-donor and the second one for the hydrogen bond in which the AA acts as H-donor).

Usually, $\mathrm{hb}$ formation is accompanied by weakening (and therefore elongation) of $\mathrm{X}-\mathrm{H}$ bond, where $\mathrm{X}$ is the $\mathrm{H}$-donor in the hydrogen-bonded complex. The magnitude of such elongation in $\mathrm{X}-\mathrm{H}$ distance is reported in Table 1. The said elongation is the least in case of the 
Table 1. Hydrogen bond $(\mathrm{H} \ldots \mathrm{Y})$ distances, elongation in $\mathrm{X}-\mathrm{H}$ distances (in $\AA$ ) during $\mathrm{X}-\mathrm{H}$. . Y hydrogen bonding interaction in polymer-AA adducts $(\mathrm{X}=\mathrm{H}$ - donor, $\mathrm{Y}=\mathrm{H}$ acceptor) calculated at M06-2X/6-31++G(d,p) level of theory.

\begin{tabular}{|c|c|c|c|c|c|c|c|c|c|c|}
\hline \multirow[t]{2}{*}{ Adduct } & \multicolumn{5}{|c|}{$\mathrm{H} \cdots \mathrm{Y}(\mathrm{hb})$ distance } & \multicolumn{5}{|c|}{ Elongation in $\mathrm{X}-\mathrm{H}$ distance } \\
\hline & Gas & $\mathrm{CCl}_{4}$ & Acetone & DMSO & Water & Gas & $\mathrm{CCl}_{4}$ & Acetone & DMSO & Water \\
\hline PCL-gly & 1.82 & 1.79 & 1.79 & 1.77 & 1.77 & 0.014 & 0.011 & & 0.009 & 0.009 \\
\hline PGA-gly & 1.81 & 1.82 & 1.83 & 1.83 & 1.83 & 0.012 & 13 & 14 & 0.014 & 0.014 \\
\hline PLA-gly & $\begin{array}{l}1.59 \\
1.64\end{array}$ & $\begin{array}{l}1.57 \\
1.62\end{array}$ & $\begin{array}{l}1.56 \\
1.63\end{array}$ & $\begin{array}{l}1.56 \\
1.63\end{array}$ & $\begin{array}{l}1.54 \\
1.65\end{array}$ & $\begin{array}{c}0.032, \\
0.042\end{array}$ & $\begin{array}{l}0.030 \\
0.040\end{array}$ & $\begin{array}{c}0.029 \\
0.041\end{array}$ & $\begin{array}{l}0.029 \\
0.041\end{array}$ & $\begin{array}{c}0.028, \\
0.043\end{array}$ \\
\hline PLGA-gly & $\begin{array}{l}1.57 \\
1.61\end{array}$ & $\begin{array}{l}1.56 \\
1.62\end{array}$ & $\begin{array}{l}1.56 \\
1.63\end{array}$ & $\begin{array}{l}1.56 \\
1.63\end{array}$ & $\begin{array}{l}1.54 \\
1.65\end{array}$ & $\begin{array}{c}0.037 \\
0.045\end{array}$ & $\begin{array}{c}0.036 \\
0.046\end{array}$ & $\begin{array}{l}0.036 \\
0.047\end{array}$ & $\begin{array}{c}0.036 \\
0.047\end{array}$ & $\begin{array}{c}0.034 \\
0.049\end{array}$ \\
\hline PCL-ala & 1.82 & 1.79 & 1.78 & 1.75 & 1.75 & 0.013 & 0.010 & 0.009 & 0.006 & 0.006 \\
\hline PGA-ala & 1.79 & 1.75 & 1.74 & 1.73 & 1.73 & 0.013 & 0.009 & 0.008 & 0.007 & 0.007 \\
\hline PLA-ala & $\begin{array}{l}1.56, \\
1.61\end{array}$ & $\begin{array}{l}1.55, \\
1.62\end{array}$ & $\begin{array}{l}1.55 \\
1.63\end{array}$ & $\begin{array}{l}1.55 \\
1.63\end{array}$ & $\begin{array}{l}1.53, \\
1.64\end{array}$ & $\begin{array}{l}0.035 \\
0.047\end{array}$ & $\begin{array}{c}0.034 \\
0.048\end{array}$ & $\begin{array}{l}0.034 \\
0.049\end{array}$ & $\begin{array}{c}0.034 \\
0.049\end{array}$ & $\begin{array}{c}0.033 \text {, } \\
0.050\end{array}$ \\
\hline PLGA-ala & $\begin{array}{l}1.57, \\
1.63\end{array}$ & $\begin{array}{l}1.56, \\
1.63\end{array}$ & $\begin{array}{l}1.56 \\
1.64\end{array}$ & $\begin{array}{l}1.56 \\
1.64\end{array}$ & $\begin{array}{l}1.54 \\
1.65\end{array}$ & $\begin{array}{l}0.033, \\
0.045\end{array}$ & $\begin{array}{l}0.032, \\
0.045\end{array}$ & $\begin{array}{c}0.033 \\
0.046\end{array}$ & $\begin{array}{c}0.033 \\
0.046\end{array}$ & $\begin{array}{l}0.031 \\
0.047\end{array}$ \\
\hline PCL-phe & 1.97 & 1.98 & & & & & & & & 0.013 \\
\hline PGA-phe & 1.83 & 1.85 & 1.84 & 1.86 & 1.86 & 0.012 & 0.01 & 0.013 & 0.015 & 0.015 \\
\hline PLA-phe & $\begin{array}{l}1.57, \\
1.60\end{array}$ & $\begin{array}{l}1.58 \\
1.63\end{array}$ & $\begin{array}{l}1.58 \\
1.64\end{array}$ & $\begin{array}{l}1.56 \\
1.65\end{array}$ & $\begin{array}{l}1.54 \\
1.65\end{array}$ & $\begin{array}{l}0.037 \\
0.046\end{array}$ & $\begin{array}{c}0.038 \\
0.049\end{array}$ & & $\begin{array}{c}0.036 \\
0.051\end{array}$ & $\begin{array}{c}0.034, \\
0.051\end{array}$ \\
\hline PLGA-phe & $\begin{array}{l}1.73 \\
1.80\end{array}$ & $\begin{array}{l}1.74 \\
1.82\end{array}$ & $\begin{array}{l}1.73, \\
1.84\end{array}$ & $\begin{array}{l}1.72, \\
1.85\end{array}$ & $\begin{array}{l}1.71 \\
1.85\end{array}$ & $\begin{array}{l}0.018 \\
0.007\end{array}$ & $\begin{array}{c}0.019 \\
0.009\end{array}$ & $\begin{array}{l}0.018, \\
0.011\end{array}$ & $\begin{array}{c}0.017 \\
0.012\end{array}$ & $\begin{array}{l}0.016 \text {, } \\
0.012\end{array}$ \\
\hline PCL-ser & 1.78 & 1.74 & 1.74 & 1.73 & 1.73 & 0.015 & 0.011 & 0.011 & 0.010 & 0.010 \\
\hline PGA-ser & 1.75 & 1.73 & 1.73 & 1.72 & 1.71 & 0.018 & 0.016 & 0.016 & 0.015 & 0.014 \\
\hline PLA-ser & $\begin{array}{l}1.58, \\
1.63\end{array}$ & $\begin{array}{l}1.58 \\
1.65\end{array}$ & $\begin{array}{l}1.59 \\
1.66\end{array}$ & $\begin{array}{l}1.57 \\
1.67\end{array}$ & $\begin{array}{l}1.54, \\
1.68\end{array}$ & $\begin{array}{c}0.031 \\
0.038\end{array}$ & $\begin{array}{c}0.031 \\
0.040\end{array}$ & $\begin{array}{c}0.032, \\
0.041\end{array}$ & $\begin{array}{c}0.030 \\
0.042\end{array}$ & $\begin{array}{c}0.027, \\
0.043\end{array}$ \\
\hline PLGA-ser & $\begin{array}{l}1.58, \\
1.59\end{array}$ & $\begin{array}{l}1.59 \\
1.61\end{array}$ & $\begin{array}{l}1.59 \\
1.61\end{array}$ & $\begin{array}{l}1.57 \\
1.63\end{array}$ & $\begin{array}{l}1.55 \\
1.63\end{array}$ & $\begin{array}{l}0.040 \\
0.042\end{array}$ & $\begin{array}{c}0.041 \\
0.044\end{array}$ & $\begin{array}{l}0.041 \\
0.044\end{array}$ & $\begin{array}{c}0.039 \\
0.046\end{array}$ & $\begin{array}{l}0.037 \\
0.046\end{array}$ \\
\hline PCL-asn & 1.80 & 1.81 & 1.83 & 1.84 & 1.84 & 0.014 & 0.015 & 0.017 & 0.018 & 0.018 \\
\hline PGA-asn & 1.82 & 1.83 & 1.85 & 1.86 & 1.86 & 0.011 & 0.012 & 0.014 & 0.015 & 0.015 \\
\hline PLA-asn & $\begin{array}{l}1.57 \\
1.59\end{array}$ & $\begin{array}{l}1.57 \\
1.58\end{array}$ & $\begin{array}{l}1.56 \\
1.60\end{array}$ & $\begin{array}{l}1.58 \\
1.61\end{array}$ & $\begin{array}{l}1.59 \\
1.61\end{array}$ & $\begin{array}{c}0.039 \\
0.046\end{array}$ & $\begin{array}{c}0.039 \\
0.045\end{array}$ & $\begin{array}{c}0.038 \\
0.047\end{array}$ & $\begin{array}{c}0.040 \\
0.048\end{array}$ & $\begin{array}{c}0.041, \\
0.048\end{array}$ \\
\hline PLGA-asn & $\begin{array}{l}1.57, \\
1.60\end{array}$ & $\begin{array}{l}1.58 \\
1.59\end{array}$ & $\begin{array}{l}1.57 \\
1.60\end{array}$ & $\begin{array}{l}1.59 \\
1.62\end{array}$ & $\begin{array}{l}1.60 \\
1.63\end{array}$ & $\begin{array}{c}0.038 \\
0.045\end{array}$ & $\begin{array}{c}0.039 \\
0.044\end{array}$ & $\begin{array}{l}0.038 \\
0.045\end{array}$ & $\begin{array}{c}0.040 \\
0.047\end{array}$ & $\begin{array}{l}0.041, \\
0.048\end{array}$ \\
\hline
\end{tabular}

adduct PLGA-phe $(0.007 \AA)$ while it is maximum in case of adduct PLA-phe (0.069 $\AA$ ).

Analysis of the optimized geometries of polymer-AA adducts suggests that there is regularity in the trend of $\mathrm{hb}$ distance shown by some polymer-AA adducts. In the case of adducts of gly and asn, the hb distance follows the order $-\mathrm{PLA} \sim \mathrm{PLGA}<\mathrm{PGA}<\mathrm{PCL}$. In adducts of ala and ser, the order is PLA $\sim$ PLGA $<$ PGA $<$ PCL. The order is slightly different for adducts of phe - PLA $<$ PLGA $<$ PCL $<$ PGA. The obtained trends can be expected to reflect the trend of the interaction energy of the chosen adducts.

\subsection{Solvent phase geometry of adducts}

In a strongly polar solvent, the AAs exist in their zwitterion forms. Therefore association geometries of the polymer-AA adducts in DMSO and water media can be expected to differ from their corresponding gas phase geometries and as such different possibilities have been explored. Initially, the optimized geometries of the AAs in each medium are compared and a trifling difference (in the range of $0.001-0.005 \AA$ ) in terms of $\mathrm{N}-\mathrm{H}$ and the $\mathrm{H}-\mathrm{O}$ distances $(\mathrm{N} \cdots \mathrm{H} \cdots \mathrm{O})$ between $-\mathrm{NH}_{3}^{+}$ and $-\mathrm{COO}^{-}$group of the zwitterion structure of a particular AA is noticed. In view of this, re-optimization of aqueous phase geometry (taking the zwitterion form of AAs into considerations) of each adduct is carried out in four solvents at M06-2X/6-31++G(d,p) level of theory. Aqueous phase geometries of a few adducts as representative examples are presented in Figure S2 (Supplementary Information). The interaction distance between the two moieties (polymer and AA) in the aqueous phase geometries of adducts ranges from $1.40 \AA$ to $2.27 \AA$. Thus akin to what happens in gas phase geometries, adduct formation between the considered polymer molecules and AAs through hb is evident in aqueous phase geometries also. In the aqueous phase geometries, 
Table 2. Amount of charge transfer $\left(\Delta \mathrm{q}_{\mathrm{H}}\right)$ taking place during polymer-AA hydrogen bonding calculated at M06-2X/6$31++\mathrm{G}(\mathrm{d}, \mathrm{p})$ level of theory.

\begin{tabular}{lcc}
\hline Adduct & Gas phase $\Delta \mathrm{q}_{\mathrm{H}}$ in au & Aqueous phase $\Delta \mathrm{q}_{\mathrm{H}}$ in au \\
\hline PCL-gly & 0.023 & 0.012 \\
PGA-gly & 0.025 & 0.009 \\
PLA-gly & $0.022,0.0226$ & $0.009,0.009$ \\
PLGA-gly & $0.021,0.022$ & $0.007,0.007$ \\
PCL-ala & 0.018 & 0.005 \\
PGA-ala & 0.021 & 0.007 \\
PLA-ala & $0.022,0.023$ & $0.008,0.0085$ \\
PLGA-ala & $0.021,0.024$ & $0.008,0.0085$ \\
PCL-phe & 0.021 & 0.0075 \\
PGA-phe & 0.024 & 0.010 \\
PLA-phe & $0.021,0.024$ & 0.0065 \\
PLGA-phe & $0.022,0.011$ & $0.01,0.004$ \\
PCL-ser & 0.022, & 0.009 \\
PGA-ser & 0.024 & 0.006 \\
PLA-ser & $0.023,0.024$ & $0.008,0.008$ \\
PLGA-ser & $0.025,0.025$ & $0.011,0.01$ \\
PCL-asn & 0.016 & 0.011 \\
PGA-asn & 0.020 & 0.009 \\
PLA-asn & $0.020,0.017$ & $0.007,0.006$ \\
PLGA-asn & $0.022,0.018$ & $0.009,0.008$ \\
PLA & &
\end{tabular}

the amino acids act as $\mathrm{H}$-donor (from $-\mathrm{NH}_{3}^{+}$) and the polymer acts as $\mathrm{H}$ acceptor in all the adducts and $\mathrm{COO}^{-}$ group of AAs is the $\mathrm{H}$-acceptor. The hb distance and the elongation in $\mathrm{X}-\mathrm{H}$ bond $(\mathrm{X}=\mathrm{N}, \mathrm{O})$ in the calculated geometries (at M06-2X/6-31++G(d,p) level of theory) are shown in Table $\mathrm{S} 1$ (Supplementary Information).

The difference in the structure of AAs in the gas (neutral) and aqueous phase (zwitterion) gives rise to optimized geometries that do not match in terms of site of interaction. Thus a comparative analysis of hb distance in the two media becomes out of context. Therefore in order to examine the effect of solvent on the geometry of the chosen adducts, solvent phase reoptimisation on the gas phase geometries are carried out at M06-2X/6-31++G(d,p) level of theory and obtained results are summarised in Table 1 . As can be construed from Table 1, increase in the dielectric constant of the medium leads to a minimal change in hb distance (maximum difference of $0.05 \AA$ ). Similar insignificant change in hb distance with changing the polarity of solvent is reported earlier also. ${ }^{31,32}$

\subsection{Charge transfer during hydrogen bonding}

Nature of an intuitively electrostatic hydrogen bonding interaction can be gauged from charge transfer $\left\{\Delta \mathrm{q}, \Delta \mathrm{q}=\mathrm{q}_{\mathrm{H}}\right.$ (adduct) $-\mathrm{q}_{\mathrm{H}}$ (H-donor) $\}$ during complexation. The amount of charge transfer essentially dictates the degree of covalency which influences the strength of interaction and thus the stability of adduct. To quantify the charge transfer involved during hb interaction in the considered adducts, we have calculated the NBO charges of the bridging hydrogen atom involved in the $\mathrm{hb}$ at M06-2X/6-31++G(d,p) level of theory in gas phase as well as in aqueous phase (by carrying out single point calculations on gas phase geometries). The amount of charge transfer taking place during the formation of hb in the considered adducts with respect to the bridging hydrogen $\left(\Delta q_{H}\right)$ in each of the chosen adduct is presented in Table 2 .

Calculated values of $\Delta \mathrm{q}_{\mathrm{H}}$ in the aqueous phase $(0.004$ to $0.012 \mathrm{au}$ ) for each adduct is much smaller than that obtained in the gas phase ( 0.011 to $0.025 \mathrm{au}$ ) and thus predicts weakening of polymer-AA interaction in aqueous phase. Furthermore, the obtained $\Delta \mathrm{q}_{\mathrm{H}}$ values (which is less than 0.25 au in most of the adducts) leads to the conclusion that the interaction between chosen AA and polymer molecules in both gas and the aqueous phase is mainly electrostatic in nature. ${ }^{33}$

\subsection{Vibrational frequency shift}

$\mathrm{Hb}$ interaction is accompanied by a weakening of $\mathrm{X}-\mathrm{H}$ bond which can be ascertained by a concomitant decrease in $\mathrm{X}-\mathrm{H}$ stretching frequency in the hydrogenbonded complex as compared to the non-interacting 
Table 3. X-H stretching frequencies $\left(\right.$ in $\mathrm{cm}^{-1}$ ) in adducts and $\mathrm{H}$-donor molecule $\left(\mathrm{in}^{-1}\right.$ ) calculated at M06-2X/6-31++G(d,p) level of theory.

\begin{tabular}{|c|c|c|c|c|c|c|}
\hline \multirow[t]{2}{*}{ Adducts } & \multicolumn{2}{|c|}{$\begin{array}{l}\mathrm{X}-\mathrm{H} \text { stretching freq } \\
\text { in adduct }\end{array}$} & \multicolumn{2}{|c|}{$\begin{array}{l}\mathrm{X} \text {-H stretching freq } \\
\text { in } \mathrm{H} \text {-donor }\end{array}$} & \multicolumn{2}{|c|}{ Magnitude of red shift } \\
\hline & Gas phase & Aqueous phase & Gas phase & Aqueous phase & Gas phase & Aqueous phase \\
\hline PCL-gly & 3530.10 & 3291.33 & 3830.36 & 3567.68 & 300.26 & 276.35 \\
\hline PGA-gly & 3589.14 & 3338.18 & 3830.36 & 3567.68 & 241.22 & 229.5 \\
\hline \multirow[t]{2}{*}{ PLA-gly } & 3153.86 & & 3830.36 & & 676.5 & \\
\hline & 2975.53 & 3187.29 & 3856.23 & 3790.64 & 880.7 & 603.35 \\
\hline \multirow[t]{2}{*}{ PLGA-gly } & 3088.77 & & 3830.36 & & 741.59 & \\
\hline & 2906.68 & 3143.46 & 3850.97 & 3790.64 & 944.29 & 647.18 \\
\hline PCL-ala & 3567.27 & & 3835.65 & & 268.38 & \\
\hline PGA-ala & 3545.02 & 3464.46 & 3835.65 & 3570.92 & 290.63 & 106.46 \\
\hline \multirow[t]{2}{*}{ PLA-ala } & 3086.53 & & 3835.65 & & 749.12 & \\
\hline & 2872.90 & 3183.16 & 3856.23 & 3790.64 & 983.33 & 607.48 \\
\hline \multirow[t]{2}{*}{ PLGA-ala } & 3142.95 & & 3835.65 & & 919.17 & \\
\hline & 2916.48 & 3155.01 & 3850.97 & 3791.12 & 934.49 & 636.11 \\
\hline PCL-phe & 3587.22 & 3338.4 & 3811.55 & 3538.48 & 224.33 & 200.08 \\
\hline PGA-phe & 3597.05 & 3406.32 & 3811.55 & 3538.48 & 214.5 & 132.16 \\
\hline \multirow[t]{2}{*}{ PLA-phe } & 3051.54 & & 3811.55 & & 760.01 & \\
\hline & 2869.00 & 3052.88 & 3856.23 & 3538.48 & 987.23 & 485.6 \\
\hline \multirow[t]{2}{*}{ PLGA-phe } & 3677.91 & & 3811.55 & & 133.64 & \\
\hline & 3442.5 & 3164.29 & 3850.97 & 3791.12 & 408.47 & 626.83 \\
\hline PCL-ser & 3493.25 & 3358.91 & 3827.03 & 3546.25 & 333.78 & 187.34 \\
\hline PGA-ser & 3427.85 & 3299.01 & 3827.03 & 3546.25 & 399.18 & 247.24 \\
\hline \multirow[t]{2}{*}{ PLA-ser } & 2985.97 & & 3827.03 & & 841.06 & \\
\hline & 3190.62 & 2675.48 & 3856.23 & 3246.25 & 665.61 & 570.77 \\
\hline \multirow[t]{2}{*}{ PLGA-ser } & 2911.97 & & 3827.03 & & 915.06 & \\
\hline & 3053.36 & 2684.81 & 3850.97 & 3246.25 & 797.61 & 561.44 \\
\hline PCL-asn & 3547.18 & 3358.71 & 3814.66 & 3500.62 & 267.48 & 141.91 \\
\hline PGA-asn & 3613.82 & 3410.45 & 3814.66 & 3500.62 & 200.84 & 90.17 \\
\hline \multirow[t]{2}{*}{ PLA-asn } & 3044.25 & & 3814.66 & & 770.41 & \\
\hline & 2875.39 & 3220.67 & 3856.23 & 3790.64 & 980.84 & 569.97 \\
\hline \multirow[t]{2}{*}{ PLGA-asn } & 3064.01 & & 3814.66 & & 750.66 & \\
\hline & 2899.34 & 3130.67 & 3850.97 & 3791.12 & 950.56 & 660.45 \\
\hline
\end{tabular}

$\mathrm{H}$-donor species. Therefore, redshifts in $\mathrm{O}-\mathrm{H}$ or $\mathrm{N}-\mathrm{H}$ stretching frequencies would provide unambiguous information regarding the formation of $\mathrm{hb}$ as well as the magnitude of redshift would reflect the extent and thus the strength of interaction in the considered adducts. The X-H stretching frequencies in adducts as well as in the respective non-interacting $\mathrm{H}$-donor molecule in both gas and the aqueous phase are provided in Table 3 . Fairly large redshifts $\left(214.5-987.23 \mathrm{~cm}^{-1}\right)$ in the X-H asymmetric stretching frequency in all the considered adducts are noticeable which highlights the formation of hb during adduct formation. Similar large spectral shifts in hydrogen-bonded systems involving nucleobases are reported in the literature. ${ }^{34,35}$ It is further apparent from Table 3 that magnitude of the spectral shift in an aqueous medium $\left(90.17-660.45 \mathrm{~cm}^{-1}\right)$ is smaller than that in the gas phase. For instance, red shift in vibrational frequency for the adduct PCL-gly in gas and the aqueous phase are 300.26 and $276.35 \mathrm{~cm}^{-1}$ respectively.
Smaller spectral shifts in aqueous phase than in gas phase is indicative of a weaker hb interaction between the considered polymers and AAs in aqueous phase than that in the gas phase and is consistent with the observation made from the analysis of charge transfer $\left(\Delta \mathrm{q}_{\mathrm{H}}\right)$ taking place during polymer-AA hydrogen bonding (Table 2).

\subsection{Interaction energy of adducts}

3.5a Gas phase interaction energy: Gas phase BSSE corrected $\Delta \mathrm{E}_{\mathrm{int}}$ values of the chosen polymer-AA adducts calculated at different levels of theory are presented in Table 4. The BSSE correction is found to be less than $6 \%$ of the respective $\Delta \mathrm{E}_{\text {int }}$ values. As for example, BSSE correction for the adduct PLGA-ala calculated at M06-2X/6-31++G(d,p) and CAM-B3LYP/6$31++\mathrm{G}(\mathrm{d}, \mathrm{p})$ level of theory are 1.01 , and $0.98 \mathrm{kcal} \mathrm{mol}^{-1}$ against $\Delta \mathrm{E}_{\text {int }}$ values of -20.26 , and $-18.44 \mathrm{kcal} \mathrm{mol}^{-1}$ 
Table 4. Gas phase values of $\Delta \mathrm{E}_{\mathrm{int}}\left(\mathrm{in} \mathrm{kcal} \mathrm{mol}^{-1}\right.$ ) of considered polymer-AA adduct calculated at different levels of theory.

\begin{tabular}{llccc}
\hline \multirow{2}{*}{ Adducts } & \multicolumn{3}{c}{ Level of Theory } \\
\cline { 2 - 5 } & M06-2X/6-31++G(d,p) & M06-2X/6-311G++(d,p) & CAM-B3LYP/6-31++G(d,p) & CAM-B3LYP/6-311G++(d,p) \\
\hline PCL-gly & -14.13 & -14.32 & -13.04 & -13.52 \\
PGA-gly & -20.73 & -20.84 & -19.72 & -20.68 \\
PLA-gly & -20.87 & -21.47 & -20.05 & -21.17 \\
PLGA-gly & -23.91 & -25.23 & -21.99 & -23.08 \\
PCL-ala & -10.86 & -10.98 & -9.61 & -9.69 \\
PGA-ala & -14.65 & -14.66 & -12.35 & -14.17 \\
PLA-ala & -18.05 & -18.07 & 15.04 & -15.38 \\
PLGA-ala & -20.26 & -20.30 & -18.44 & -18.70 \\
PCL-phe & -10.47 & -10.75 & -12.17 & -13.09 \\
PGA-phe & -18.79 & -18.78 & -16.89 & -16.93 \\
PLA-phe & -18.77 & -18.19 & -17.42 & -17.68 \\
PLGA-phe & -15.47 & -17.61 & -13.0 & -13.13 \\
PCL-ser & -11.71 & -14.84 & -10.64 & -10.89 \\
PGA-ser & -12.51 & -13.44 & -11.79 & -12.01 \\
PLA-ser & -18.70 & -20.20 & -17.31 & -17.61 \\
PLGA-ser & -20.77 & -21.26 & -18.66 & -18.86 \\
PCL-asn & -11.27 & -11.40 & -10.04 & -10.28 \\
PGA-asn & -18.29 & -18.33 & -17.39 & -17.38 \\
PLA-asn & -18.66 & -19.02 & -17.41 & -18.04 \\
PLGA-asn & -23.20 & -23.81 & -21.77 & -22.05 \\
\hline
\end{tabular}

respectively. The $\Delta \mathrm{E}_{\text {int }}$ values are found negative in each adduct and thus adduct formation between AAs with the chosen carrier molecules is perceptibly exergonic. $\Delta \mathrm{E}_{\text {int }}$ values of adducts with gly, ala, ser and asn follow the same order, PLGA-AA > PLA-AA > PGAAA $>$ PCL-AA (AA=gly, ala, ser and asn). For adducts of phe, the order is PGA-phe > PLA-phe > PLGAphe $>$ PCL-phe. On comparing the trends of $\Delta E_{\text {int }}$ and hb distances it is apparent that in case of adducts of three AAs, gly, ala and ser only, the observed trends are corroborative with the common BL-BE relationship, i.e., shortest bond length leads to highest $\Delta \mathrm{E}_{\text {int }}$. The results further underline greater binding ability of PLGA with respect to most of the chosen AA in vacuum. PLGA has a superior bio-degradability (degradation in weeks) over the other three polymers (degradation in months and years). ${ }^{36}$ The observed trend in $\Delta \mathrm{E}_{\text {int }}$ values can also be correlated with the magnitude of charge transfer $\Delta \mathrm{q}_{\mathrm{H}}$ values provided in Table 1 . In adducts of all the chosen AAs there is a clear consistency in between the trends shown by these two parameters; in all instances, higher the value of $\Delta \mathrm{q}_{\mathrm{H}}$, greater is $\Delta \mathrm{E}_{\text {int }}$. For example, in case of adducts of gly, ala, ser and asn, $\Delta \mathrm{q}_{\mathrm{H}}$ values follow the order, PLGA-AA > PLA-AA $>$ PGA-AA > PCL-AA (AA=gly, ala, ser and asn) which is identical with the one shown by $\Delta \mathrm{E}_{\text {int }}$ values. Trends in $\Delta \mathrm{E}_{\text {int }}$ values in adducts of phe are also in qualitative agreement with their respective $\Delta q_{H}$ values. It is thus apparent that charge transfer plays a more prominent role in governing the strength of interaction of the chosen polymers with AAs than the hb distance of adduct.

3.5b Effect of variation of functional and basis set on interaction energy: To check the consistency of $\Delta \mathrm{E}_{\text {int }}$ results obtained at $\mathrm{M} 06-2 \mathrm{X} / 6-31++\mathrm{G}(\mathrm{d}, \mathrm{p})$ level of theory as well as to assess the impact of variation of functional and basis set used in calculation of $\Delta \mathrm{E}_{\text {int }}$, calculations are repeated with a long-range corrected functional CAM-B3LYP using both 6-31++G(d,p) and 6-311++G(d,p) basis sets. Obtained results are summarized in Table 4. As can be construed from Table 4, the $\Delta \mathrm{E}_{\text {int }}$ values obtained with M06-2X functional is higher than that obtained with CAM-B3LYP functional. For instance, $\Delta \mathrm{E}_{\text {int }}$ values of the adduct PGAgly, calculated by M06-2X and CAM-B3LYP functional using $6-31++\mathrm{G}(\mathrm{d}, \mathrm{p})$ basis set are -20.76 , and $-19.72 \mathrm{kcal} \mathrm{mol}^{-1}$ respectively. M06-2X has become wise alternatives to the computationally demanding high-level theoretical methods like MP2 or couple cluster (cc) in providing an accurate description of noncovalent interactions such as hydrogen bonding. ${ }^{37-39}$ In assessing the performance of dispersion-corrected DFT methods for estimating hydrogen bonding interaction energies in hb23 dimers of S66 benchmark, DiLabio et al., reported a greater efficacy of M06-2X functional in terms of accuracy and cost-effectiveness. ${ }^{40}$ 
Table 5. Solvent phase interaction energy (in $\mathrm{kcal} \mathrm{mol}^{-1}$ ) of polymer-AA adducts calculated by re-optimizing gas phase geometry of adducts in four solvents using M06-2X/6-31++G(d,p) levels of theory.

\begin{tabular}{lcccc}
\hline Adducts & Carbon tetrachloride & Acetone & DMSO & Water \\
\hline PCL-gly & -12.56 & -12.24 & -11.45 & -11.41 \\
PGA-gly & -18.33 & -18.30 & -16.66 & -16.55 \\
PLA-gly & -19.11 & -18.26 & -17.13 & -16.88 \\
PLGA-gly & -22.55 & -17.60 & -17.25 & -17.19 \\
PCL-ala & -10.08 & -8.55 & -6.68 & -6.62 \\
PGA-ala & -13.32 & -10.29 & -8.72 & -8.62 \\
PLA-ala & -17.35 & -15.63 & -12.61 & -12.52 \\
PLGA-ala & -18.28 & -16.20 & -13.54 & -13.28 \\
PCL-phe & -9.75 & -8.85 & -7.04 & -6.98 \\
PGA-phe & -16.21 & -11.73 & -11.33 & -11.20 \\
PLA-phe & -16.08 & -10.65 & -12.57 & -12.48 \\
PLGA-phe & -14.34 & -11.71 & -9.32 & -9.26 \\
PCL-ser & -10.65 & -8.54 & -7.34 & -7.27 \\
PGA-ser & -11.69 & -9.66 & -7.25 & -7.16 \\
PLA-ser & -17.85 & -15.49 & -13.18 & -13.10 \\
PLGA-ser & -19.41 & -15.69 & -12.69 & -12.60 \\
PCL-asn & -10.88 & -10.20 & -6.72 & -6.65 \\
PGA-asn & -16.56 & -13.97 & -10.83 & -10.70 \\
PLA-asn & -17.55 & -14.85 & -11.43 & -11.26 \\
PLGA-asn & -21.56 & -17.05 & -15.20 & -15.04 \\
\hline
\end{tabular}

Inclusion of the triple zeta basis set instead of double zeta one results in marginally higher $\Delta \mathrm{E}_{\text {int }}$ values (the difference is $<1 \mathrm{kcal} \mathrm{mol}^{-1}$ ) in most of the adducts.

As for example, $\Delta \mathrm{E}_{\text {int }}$ values obtained for the adduct PGA-asn are -18.29 and $-18.33 \mathrm{kcal} \mathrm{mol}^{-1}$ at M062X/6-31++G(d,p) and M06-2X/6-311++G(d,p) level of theories respectively. The observed results thus accentuate the significance of the level of theory used in the calculation of $\Delta \mathrm{E}_{\text {int }}$ of hydrogen-bonded adducts of $\mathrm{AAs}$ with synthetic polymers as considered in the present study.

3.5c Effect of solvent on interaction energy: The effect of solvent on $\Delta \mathrm{E}_{\text {int }}$ is critical for systems/adducts possessing biomedical applications. For the sake of uniformity and convenience of comparability, re-optimization of all the gas phase association geometries using the polarizable continuum model (PCM) has been performed (at the same level of theory) in carbon tetrachloride, acetone, DMSO and water. In case of solvent phase calculations involving aqueous phase association geometries (taking the zwitterionic form of amino acids) single point calculations are performed on aqueous phase optimized geometries in the four chosen solvents. To validate the results two adducts PCL-gly and PCL-ala were re-optimized in different solvents; however, calculated interaction energy did not differ considerably from that obtained by single point calculations. Obtained solvent phase $\Delta \mathrm{E}_{\text {int }}$ values in carbon tetrachloride, acetone, DMSO and water media by considering the gas phase geometry of adducts are presented in Table 5 while those obtained by considering zwitter-ion form of AAs are summarized in Table S2 (Supplementary Information).

Results suggest a marginal to a significant reduction of interaction energy with increasing dielectric of the medium, depending on the identity of the adduct.

For example, at M06-2X/6-31++G(d,p) level of theory, $\Delta \mathrm{E}_{\text {int }}$ values (in kcal mol ${ }^{-1}$ ) of PLGA-ser in gas, carbon tetrachloride, DMSO and water are -20.77 , $-19.41,-15.69,-12.69$ and $-12.60 \mathrm{kcal} \mathrm{mol}^{-1}$ respectively. For the PCL-phe adduct, these values (in $\mathrm{kcal} \mathrm{mol}^{-1}$ ) are -10.47 (gas), -9.75 (carbon tetrachloride), -8.85 (acetone), -7.04 (DMSO) and -6.98 (water). It is important to note that almost in all cases solvent phase $\Delta \mathrm{E}_{\text {int }}$ values obtained for aqueous phase geometry of adducts are less than their corresponding values of gas phase geometries. For instance, the $\Delta \mathrm{E}_{\text {int }}$ values (in $\mathrm{kcalmol}^{-1}$ ) of adducts with gly in water medium, obtained with gas/aqueous phase geometries are- PCL-gly: $-11.41 /-5.52$, PGA-gly: - 16.55/ - 7.65, PLA-gly: - 16.88/ - 12.92 and PLGA-gly: - 17.19/ - 13.53. However, the trend in the response of $\Delta \mathrm{E}_{\text {int }}$ values against an increase in 
Table 6. Thermo-chemical parameters (in kcal $\mathrm{mol}^{-1}$ ) of polymer-AA adducts calculated at M06$2 \mathrm{X} / 6-31++\mathrm{G}(\mathrm{d}, \mathrm{p})$ level of theory.

\begin{tabular}{|c|c|c|c|c|}
\hline \multirow[t]{2}{*}{ Adducts } & \multicolumn{2}{|c|}{ Gas phase } & \multicolumn{2}{|c|}{ Aqueous phase } \\
\hline & $\Delta \mathrm{H}_{\mathrm{int}}$ & $\Delta \mathrm{G}_{\mathrm{int}}$ & $\Delta \mathrm{H}_{\mathrm{int}}$ & $\Delta G_{\text {int }}$ \\
\hline PCL-gly & -15.03 & -10.89 & -6.22 & 4.66 \\
\hline PGA-gly & -19.98 & -5.14 & -6.23 & 4.42 \\
\hline PLA-gly & -19.59 & -7.24 & -12.46 & -2.94 \\
\hline PLGA-gly & -21.30 & -10.54 & -12.92 & -1.82 \\
\hline PCL-ala & -9.17 & 0.81 & -6.35 & 4.26 \\
\hline PGA-ala & -13.71 & -0.41 & -4.98 & 7.39 \\
\hline PLA-ala & -18.28 & -4.30 & -13.33 & -3.10 \\
\hline PLGA-ala & -19.15 & -8.75 & -12.99 & -1.90 \\
\hline PCL-phe & -10.01 & 5.86 & -5.39 & 4.73 \\
\hline PGA-phe & -17.41 & -5.43 & -6.25 & 5.76 \\
\hline PLA-phe & -17.50 & -4.20 & -7.27 & 1.79 \\
\hline PLGA-phe & -14.85 & -1.86 & -6.22 & -0.29 \\
\hline PCL-ser & -9.94 & 1.64 & -4.96 & 4.32 \\
\hline PGA-ser & -11.10 & -0.09 & -4.89 & 5.85 \\
\hline PLA-ser & -17.54 & -5.74 & -11.46 & -0.38 \\
\hline PLGA-ser & -19.14 & -8.85 & -11.33 & -0.17 \\
\hline PCL-asn & -10.45 & 1.64 & -7.35 & 3.82 \\
\hline PGA-asn & -16.67 & -2.36 & -6.93 & 4.24 \\
\hline PLA-asn & -18.31 & -4.62 & -12.33 & -1.63 \\
\hline PLGA-asn & -21.53 & -9.76 & -12.06 & -0.18 \\
\hline
\end{tabular}

dielectric constant of media is observed to be similar. The obtained results thus suggest that the incorporation of solvent leads to a drop in $\Delta \mathrm{E}_{\text {int }}$ for each of the modelled system. Spiky fall in $\Delta \mathrm{E}_{\text {int }}$ upon solvation in adducts containing charged species, for example, cation$\pi$ complexes of thiophene $\left(\sim 35 \mathrm{kcal} \mathrm{mol}^{-1}\right)^{41}, \mathrm{~B} \equiv \mathrm{B}$ triple bond $\left(\sim 70 \mathrm{kcal} \mathrm{mol}^{-1}\right),{ }^{42}$ or CS -asp adducts $\left(\sim 90 \mathrm{kcalmol}^{-1}\right)^{29}$ are previously reported. However, incorporation of water as a solvent produced a marginal fall in $\Delta \mathrm{E}_{\mathrm{int}}\left(<1 \mathrm{kcal} \mathrm{mol}^{-1}\right)$ in neutral adducts involving $\mathrm{B}-\mathrm{H} \cdot \cdots \pi$ interaction. ${ }^{43}$ Notably there is a small difference in $\Delta \mathrm{E}_{\mathrm{int}}$ of the adducts in DMSO and in water. Solvent phase $\Delta \mathrm{E}_{\text {int }}$ results thus delineate an immediate destabilization of a polymer-AA complex as it traverses from non-polar protein-lipid bi-layer of the cell membrane to polar cytoplasm environment.

\subsection{Thermo-chemical analysis}

3.6a Binding enthalpy and free energy of adduct formation: To examine the feasibility of adduct formation as well as the thermodynamic stability of the chosen polymer-AA adducts, binding enthalpy $\left(\Delta \mathrm{H}_{\text {int }}\right)$ and free energy of adducts formation $\left(\Delta \mathrm{G}_{\text {int }}\right)$ with respect to each adduct have been calculated and obtained results are presented in Table 6.

Referred to Table 6 , negative $\Delta H_{\text {int }}$ values for all the chosen adducts predict exothermic nature of adducts formation in vacuo as well as in aqueous medium. A close agreement between the $\Delta \mathrm{H}_{\text {int }}$ and $\Delta \mathrm{E}_{\text {int }}$ values as well as resemblance in their trend with respect to adducts of a particular AA in both media is noteworthy. As for example, for adducts of gly, the gas phase $\Delta \mathrm{H}_{\text {int }} / \Delta \mathrm{E}_{\text {int }}$ values (in $\mathrm{kcal} \mathrm{mol}^{-1}$ ) are; $-15.03 /$ - 10.89 for PCL-gly, - 14.30/ - 12.32 for PGA-gly, -19.59 / - 7.24 for PLA-gly and $-21.30 /-10.54$ for PLGA-gly. For adducts of other AAs also, the same consistency is observed. Since in the absence of experimental or any benchmark data for validation is available, a close agreement between the variation pattern of $\Delta \mathrm{E}_{\text {int }}$ and $\Delta \mathrm{H}_{\text {int }}$ values of adducts adds credence to a theoretical calculation, obtained $\Delta \mathrm{H}_{\text {int }}$ values reinforce the stability trend predicted by the $\Delta \mathrm{E}_{\text {int }}$ values of adducts. Furthermore, as observed in the case of $\Delta \mathrm{E}_{\text {int }}$ values, a spiky fall in $\Delta \mathrm{H}_{\text {int }}$ of each adduct is noticed in aqueous phase from their respective gas phase values. This result further substantiates lower thermodynamic stability of the considered adducts in polar solvents.

Similar to the $\Delta \mathrm{H}_{\mathrm{int}}$, gas phase values of free energy change $\left(\Delta \mathrm{G}_{\text {int }}\right)$ upon adducts formation (Table 6 ) obtained for majority of adducts are negative, which suggest the feasibility of formation of the considered polymer-AA adducts via electrostatic interaction and more precisely hydrogen bonding. During adducts formation, the entropy of the system decreases and this opposes a negative $\Delta G$ value which leads to less negative or even positive gas and aqueous phase $\Delta \mathrm{G}_{\text {int }}$ values in a few adducts. Along the same line with $\Delta \mathrm{E}_{\text {int }}$ values and $\Delta \mathrm{H}_{\text {int }} ; \Delta \mathrm{G}_{\text {int }}$ values also predict the comparatively greater stability of PLGA-AA adducts as inferred from their relatively higher negative $\Delta \mathrm{G}_{\text {int }}$ values in the gas phase and negative values for adducts with all the chosen AAs. Calculated $\Delta \mathrm{G}_{\text {int }}$ values thus confirm that adduct formation between the chosen AAs and polymers is enthalpy driven.

\section{Conclusions}

The present study enumerates the interaction of four synthetic polymers with five amino acids carried out in an attempt to study protein delivery by the chosen polymers. Structure analysis and study of vibrational frequency establish the central role of hydrogen bonding during adduct formation between the two interacting species. Change in polarity of solvent fails to impinge on the hydrogen bond distance between a polymer and AA. Fairly large spectral (red) shifts in adducts are observed. In aqueous phase, magnitude of 
red shift becomes smaller which is indicative of the weakening of interaction between the polymer and AAs in solution than in vacuo. Interaction energy calculated in the gas phase as well as in four different solvents suggest that adduct formation by the considered polymers PCL, PGA, PLA and PLGA with the amino acids are essentially exergonic in nature. Insertion of solvents leads to lowering of interaction energy and thus stability of the considered adducts is sensitive toward the dielectric of the prevailing media. Calculated values of important thermo-chemical parameters lead to the conclusion that adduct formation process is enthalpy driven. Stability of adducts of a particular amino acid depends on the identity of the interacting polymer. Results of interaction energy and thermochemical parameters of the adducts in gas and solvent phases substantiate the potentiality of each of the considered polymers as protein delivery vector. Greater suitability of PLGA as amino acid carrier in comparison to other three is in agreement with previous experimental study.

\section{Supplementary Information (SI)}

Figures S1, S2 and Tables S1, S2 are available as Supplementary Information at www.ias.ac.in/chemsci.

\section{Acknowledgements}

Authors sincerely acknowledge the Department of Science and Technology, New Delhi, India (Grant No. SB/S1/PC17/2014) for providing the computational set-up required for the study.

\section{References}

1. Jain A, Gulbake A, Shilpi S, Hurkat P and Jain S K 2013 Peptide and protein delivery using new drug delivery systems Crit. Rev. Ther. Drug Carrier Syst. 30293

2. Wise D L, Fellmann T D, Sanderson J E and Wentworth R L 1979 Lactic/glycolic acid polymers In Drug carriers in biology and medicine (London: Academic) p. 237

3. Mohamed F and van der Walle C F 2008 Engineering biodegradable polyester particles with specific drug targeting and drug release properties J. Pharm. Sci. 9771

4. Scott R C, Crabbe D, Krynska B, Ansari R and Kiani M F 2008 Aiming for the heart: targeted delivery of drugs to diseased cardiac tissue Expert Opin. Drug Deliv. 5459

5. Wei Q, Becherer T, Angioletti-Uberti S, Dzubiella J, Wischke C, Neffe A T, Lendlein A, Ballauff M and Haag R 2014 Protein interactions with polymer coatings and biomaterials Angew. Chem. Int. Edit. 538004

6. Jagur-Grodzinski J 1999 Biomedical application of functional polymers React. Funct. Polym. 3999

7. Kim S Y, Lee Y M, Baik D J and Kang J S 2003 Toxic characteristics of methoxy poly (ethylene glycol)/poly
( $\varepsilon$-caprolactone) nanospheres; in vitro and in vivo studies in the normal mice Biomaterials 2455

8. Lanao R P F, Jonker A M, Wolke J G, Jansen JA, van Hest J C and Leeuwenburgh S C 2013 Physicochemical properties and applications of poly (lactic-co-glycolic acid) for use in bone regeneration Tissue Eng. Part B: Rev. 19380

9. Teupe C, Meffert R, Winckler S, Ritzerfeld W, Törmälä $\mathrm{P}$ and Brug E 1992 Ciprofloxacin-impregnated poly-Llactic acid drug carrier Arch. Orthop. Trauma Surg. 112 33

10. Benoit M-A, Baras B and Gillard J 1999 Preparation and characterization of protein-loaded poly ( $\varepsilon$-caprolactone) microparticles for oral vaccine delivery Int. J. Pharm. 18473

11. Mukerjee A, Pruthi V and Sinha V 2006 Preparation and characterization of poly- $\varepsilon$-caprolactone carrier particles for controlled insulin delivery Biomedical and Pharmaceutical Engineering ICBPE International Conference on, IEEE 276-279

12. Puhl S, Li L, Meinel L and Germershaus O 2014 Controlled protein delivery from electrospun non-wovens: novel combination of protein crystals and a biodegradable release matrix Mol. Pharm. 112372

13. Wang F, Liu X, Yuan J, Yang S, Li Y and Gao Q 2016 Synthesis and characterization of poly (lactic acid-coglycolic acid) complex microspheres as drug carriers $J$. Biomater. Appl. 31544

14. Li M, Neoh K G, Kang E T, Lau T and Chiong E 2014 Surface modification of silicone with covalently immobilized and crosslinked agarose for potential application in the inhibition of infection and omental wrapping $A d v$. Funct. Mater. 241631

15. Liu Y, Yin $Y$, Wang L, Zhang W, Chen X, Yang X, Xu J and Ma G 2013 Engineering biomaterialassociated complement activation to improve vaccine efficacy Biomacromolecules 143321

16. Costa D, Garrain P A and Baaden M 2013 Understanding small biomolecule-biomaterial interactions: A review of fundamental theoretical and experimental approaches for biomolecule interactions with inorganic surfaces $J$. Biomed. Mat. Res. Part A 1011210

17. Rabe M, Verdes D and Seeger S 2011 Understanding protein adsorption phenomena at solid surfaces $A d v$. Colloid Interface Sci. 16287

18. Qu Z G, He X C, Lin M, Sha B Y, Shi X H, Lu T J and Xu F 2013 Advances in the understanding of nanomaterialbiomembrane interactions and their mathematical and numerical modeling Nanomedicine 8995

19. Jeyachandran Y, Mielczarski E, Rai B and Mielczarski J 2009 Quantitative and qualitative evaluation of adsorption/desorption of bovine serum albumin on hydrophilic and hydrophobic surfaces Langmuir 2511614

20. Lu D R, Lee S J and Park K 1992 Calculation of solvation interaction energies for protein adsorption on polymer surfaces J. Biomater. Sci. Polym. Ed. 3127

21. O'Brien C, Stuart S, Bruce D and Latour R 2008 Modeling of peptide adsorption interactions with a poly (lactic acid) surface Langmuir $\mathbf{2 4} 14115$

22. Raffaini $\mathrm{G}$ and Ganazzoli F 2007 Understanding the performance of biomaterials through molecular modeling: crossing the bridge between their intrinsic properties and 
the surface adsorption of proteins Macromol. Biosci. 7 552

23. Zhang L, Zhao G and Sun Y 2009 Molecular insight into protein conformational transition in hydrophobic charge induction chromatography: a molecular dynamics simulation J. Phys. Chem. B $\mathbf{1 1 3} 6873$

24. Liu Y, Wu M, Feng X, Shao X and Cai W 2012 Adsorption behavior of hydrophobin proteins on polydimethylsiloxane substrates J. Phys. Chem. B 11612227

25. Politzer P and Murray J S 2002 The fundamental nature and role of the electrostatic potential in atoms and molecules Theor. Chem Acc. $\mathbf{1 0 8} 134$

26. Boys S F and Bernardi F D 1970 The calculation of small molecular interactions by the differences of separate total energies. Some procedures with reduced errors Mol. Phys. 19553

27. Tomasi J and Persico M 1994 Molecular interactions in solution: an overview of methods based on continuous distributions of the solvent Chem. Rev. 942027

28. Frisch M J, Trucks G W, Schlegel H B, Scuseria G E, Robb M A, Cheeseman J R, Scalmani G, Barone V, Mennucci B, Petersson G A, Nakatsuji H, Caricato M, Li X, Hratchian H P, Izmaylov A F, Bloino J, Zheng G, Sonnenberg J L, Hada M, Ehara M, Toyota K, Fukuda R, Hasegawa J, Ishida M, Nakajima T, Honda Y, Kitao O, Nakai H, Vreven T, Montgomery J A, Peralta J E Jr., Ogliaro F, Bearpark M, Heyd J J, Brothers E, Kudin K N, Staroverov V N, Kobayashi R, Normand J, Raghavachari K, Rendell A, Burant J C, Iyengar S S, Tomasi J, Cossi M, Rega N, Millam J M, Klene M, Knox J E, Cross J B, Bakken V, Adamo C, Jaramillo J, Gomperts R, Stratmann R E, Yazyev O, Austin A J, Cammi R, Pomelli C, Ochterski J W, Martin R L, Morokuma K, Zakrzewski V G, Voth G A, Salvador P, Dannenberg J J, Dapprich S, Daniels A D, Farkas Ö, Foresman J B, Ortiz J V, Cioslowski J and Fox D J Gaussian 09 (Gaussian, Inc., Wallingford CT, 2009).

29. Deka B C and Bhattacharyya P K 2017 DFT study on host-guest interaction in chitosan-amino acid complexes Comput. Theor. Chem. 111040

30. Saha B and Bhattacharyya P K 2016 Adsorption of amino acids on boron and/or nitrogen doped functionalized graphene: A Density Functional Study Comput. Theor. Chem. 108645

31. Hwang S-G and Chung D-S 2005 Calculation of the solvation free energy of the proton in methanol Bull. Korean Chem. Soc. 26589
32. Deka B C and Bhattacharyya P K 2016 Reactivity of chitosan derivatives and their interaction with guanine: A computational study J. Chem. Sci. 128589

33. Sarma D, Saha B, Deka B C and Bhattacharyya P K 2016 Unique cation-cyclohexane interactions in tri- and hexa-fluorocyclohexane multidecker complexes in the gas phase: a DFT study RSC Adv. 6111856

34. Fornaro T, Biczysko M, Monti S and Barone V 2014 Dispersion corrected DFT approaches for anharmonic vibrational frequency calculations: nucleobases and their dimers Phys. Chem. Chem. Phys. 1610112

35. Plützer C, Hünig I, Kleinermanns K, Nir E and de Vries M S 2003 Pairing of Isolated Nucleobases: Double Resonance Laser Spectroscopy of Adenine-Thymine Chem. Phys. Chem. 4838

36. Banga A K 2015 In Therapeutic peptides and proteins: Formulation, processing, and delivery systems (Boca Raton: CRC Press)

37. Minenkov Y, Singstad $\AA$, Occhipinti G and Jensen V R 2012 The accuracy of DFT-optimized geometries of functional transition metal compounds: a validation study of catalysts for olefin metathesis and other reactions in the homogeneous phase Dalton Trans. 415526

38. Zhao Y and Truhlar D G 2008 The M06 suite of density functionals for main group thermochemistry, thermochemical kinetics, noncovalent interactions, excited states, and transition elements: two new functionals and systematic testing of four M06-class functionals and 12 other functionals Theor. Chem. Acc. 120215

39. Chai J-D and Head-Gordon M 2008 Long-range corrected hybrid density functionals with damped atomatom dispersion corrections Phys. Chem. Chem. Phys. 106615

40. DiLabio G A and Johnson E R, Otero-de-la-Roza A 2013 Performance of conventional and dispersion-corrected density-functional theory methods for hydrogen bonding interaction energies Phys. Chem. Chem. Phys. 1512821

41. Deka B C, Purkayastha S K and Bhattacharyya P K 2016 Formation of thiophene sandwiches through cation- $\pi$ interaction: A DFT study Comput. Theor. Chem. 1095 83

42. Bhattacharyya P K 2017 Exploring Cation-Interaction in the Complexes with BB Triple Bond: A DFT Study $J$. Phys. Chem. A 1213287

43. Bhattacharyya P K 2017 BH b $\cdots \pi$ interactions in benzene-borazine sandwich and multidecker complexes: a DFT study New J. Chem. 411293 